\begin{tabular}{|c|c|}
\hline \multirow{3}{*}{ 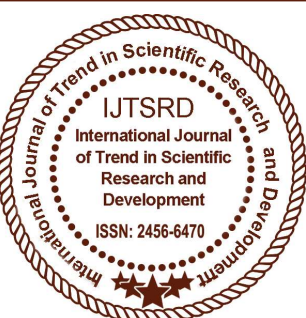 } & $\begin{array}{l}\text { International Journal of Trend in Scientific } \\
\text { Research and Development (IJTSRD) }\end{array}$ \\
\hline & International Open Access Journal \\
\hline & ISSN No: 2456 - 6470 | www.ijtsrd.com | Volume - 2 | Issue - 5 \\
\hline
\end{tabular}

\title{
Heritability of Blood Pressure Among Random Adult Individuals of South Indian States
}

\author{
Dr. V Venugopal Rao ${ }^{1}$, P Brinda ${ }^{2}$, R Keerthana ${ }^{2}$, B Mounika ${ }^{2}$ \\ ${ }^{1} \mathrm{HoD}$, Genetics, ${ }^{2}$ Students of B Sc (GCZ) III Year \\ St. Ann's College for Women, Mehdipatnam, Hyderabad, Telangana, India
}

\begin{abstract}
Hypertension is considered to be a major health concern and a threat for mortality and morbidity in individuals caused due to myocardial infarction, stroke and other cardiovascular diseases. Our study comprises of 200 randomly chosen nuclear families from five different South Indian states during the period of June, 2016 to December, 2017. A total of 750 individuals (both parents and off spring) are studied. About 103 families are selected from Telangana State, 25 families from Andhra Pradesh State, 13 families from Tamil Nadu State, 35 families from Karnataka State and 24 families from Kerala State. Information is gathered from each member of the family and Blood Pressure is measured. A linear fit is tried and regression coefficients are estimated and found to be significant using student's t-test and F-test. The linear equation $\mathrm{Y}=\mathrm{a}+\mathrm{bx}$ is taken where $\mathrm{x}$ is mid parental value and $\mathrm{Y}$ is average of offspring and regression of offspring on mid parental value is equal to heritability. The regression coefficient and $\mathrm{R} 2$ values $(0.271, \mathrm{t}$ and $\mathrm{F} ; \mathrm{P}<0.05$ and 0.074$)$ for diastolic blood pressure are higher than those values $(0.083, \mathrm{t}$ and $\mathrm{F} ; \mathrm{P}<0.05$ and 0.031$)$ for systolic blood pressure indicating that Diastolic blood pressure is more genetically determined than Systolic blood pressure.
\end{abstract}

Keywords: Blood Pressure, Heritability, Regression Model.

\section{INTRODUCTION}

In today's world, an alarming threat for mortality and morbidity in individuals caused due to myocardial infarction, stroke and other cardiovascular diseases is an elevation in Blood Pressure. (P P Majumder et al., 1990; A Nirmala et al., 1992; P Majumder et al.,
1994; Dayananda and Murthy, 2009; Alwan et al., 2015). Hypertension is considered to be a major health concern in many countries. (P P Majumder et al., 1990; P P Majumder et al., 1994). Our country India is no exception to this health concern.

Measured systolic and diastolic Blood pressure in any normal healthy individual is $120 \mathrm{~mm} \mathrm{Hg}$ and $80 \mathrm{~mm}$ $\mathrm{Hg}$ (M Singh et al., 2016). Increase or decrease in this measurement of blood pressure leads to significant health problems. Though, India is a country with diverse cultural, traditional and geographical backgrounds, the contributing factors for blood pressure changes seems to be common in all these populations, still population-specific factors also exist (P P Majumder et al., 1990; P P Majumder et al., 1994).

Our main objective is to estimate the amount of genetic determination of blood pressure taking into account the resemblance and variation existing between Parents and offspring. In other words we have made an attempt to predict the heritability of this quantitative trait using regression model where the regression of the mean of offspring on mid parental value is estimated. An alternative approach to measure heritability is based on additive genetic variance. A ratio of additive genetic variance to the total phenotypic variance gives the heritability estimate which is population - specific and the phenotypic variance in turn is influenced by environmental conditions (Alwan et al., 2015).

\section{Materials and Methods:}

Our study includes parents and offspring from random nuclear families residing in metropolitan cities of 
South Indian states. The blood pressure of each individual in the family is measured and heritability is estimated.

The study comprises of 200 randomly chosen nuclear families from five different South Indian states during the period of June, 2016 to December, 2017. A total of 750 individuals (both parents and off spring) are studied. About 103 families are selected from Telangana State, 25 families from Andhra Pradesh State, 13 families from Tamil Nadu State, 35 families from Karnataka State and 24 families from Kerala State. A questionnaire is filled in by each family and data of each individual is gathered. The questionnaire includes the information like age, gender, blood group, occupation, habits viz., smoking, chewing tobacco, alcohol consumption, use of antihypertensive drugs, colour of eyes and skin, type and texture of hair, food habits and various other anthropometric measurements like height, weight, etc., Also the data on the consumption of oil, milk, salt, sugar and ghee per family was also collected. Since the studied population is from urban areas, we made a note of the health issues of each individual (if an individual suffers from any allergy or a medical history of any diseases or surgeries). We are considering only one independent variable i.e., Mid - Parental value in our Regression analysis. Blood pressure of each individual in the family is measured using standard mercury sphygmomanometer. Two readings are taken with an interval of 10 minutes and mean of the two readings are considered. The data of offspring about $18 y r s$ and above are only considered. Statistical Analysis was done manually and by using Microsoft Excel.

\section{Results and Discussion:}

A linear fit is tried and regression coefficients are estimated and found to be significant using student's t-test and F-test (Jerold H Zar (1999). Biostatistical Analysis. $4^{\text {th }}$ Edition). The regression coefficient and $\mathrm{R}^{2}$ values $(0.271, \mathrm{t}$ and $\mathrm{F} ; \mathrm{P}<0.05$ and 0.074$)$ for diastolic blood pressure are higher than those values $(0.083, t$ and $F ; P<0.05$ and 0.031$)$ for systolic blood pressure. This may indicate higher genetic determination in the case of diastolic blood pressure which is always a risk factor in determining Hypertension. There are only few individuals (3 to 4 ) whose values are 100 and above in the case of diastolic blood pressure indicating that they are hypertensive. Quite a good number of individuals belong to the range of 90 to 100 of diastolic blood pressure are prone to hypertension. A similar range for mild essential hypertension is reported in an earlier study (P P Majumder et al., 1994; Sarkar and Singh, 2015; M Singh et al., 2016). Only few individuals are prone to low blood pressure which could be 60 and less for diastolic blood pressure. The intercept value for diastolic blood pressure (57.00) could be the least possible diastolic blood pressure in this population [Fig 1]

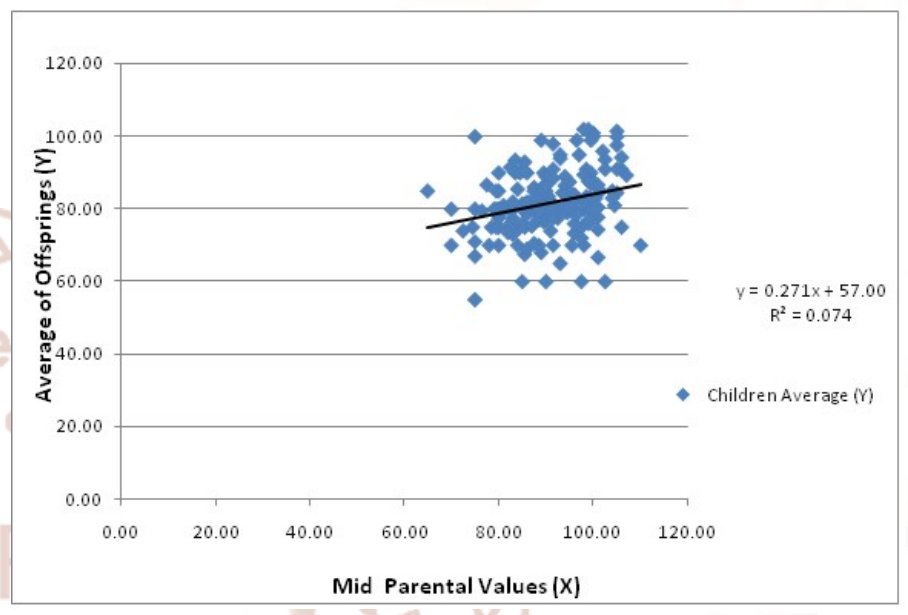

Figure1. Regression analysis for Diastolic Blood Pressure

A few individuals are in the range of $140 \mathrm{~mm} \mathrm{Hg}$ and above may be prone to hypertension. As such no one is hypertensive with systolic blood pressure greater than $160 \mathrm{~mm} \mathrm{Hg}$, the range was earlier suggested by $\mathrm{P}$ $P$ Majumder et al., 1994. The intercept value for systolic blood pressure (104.1) could be the least possible systolic blood pressure in this population [Fig 2]

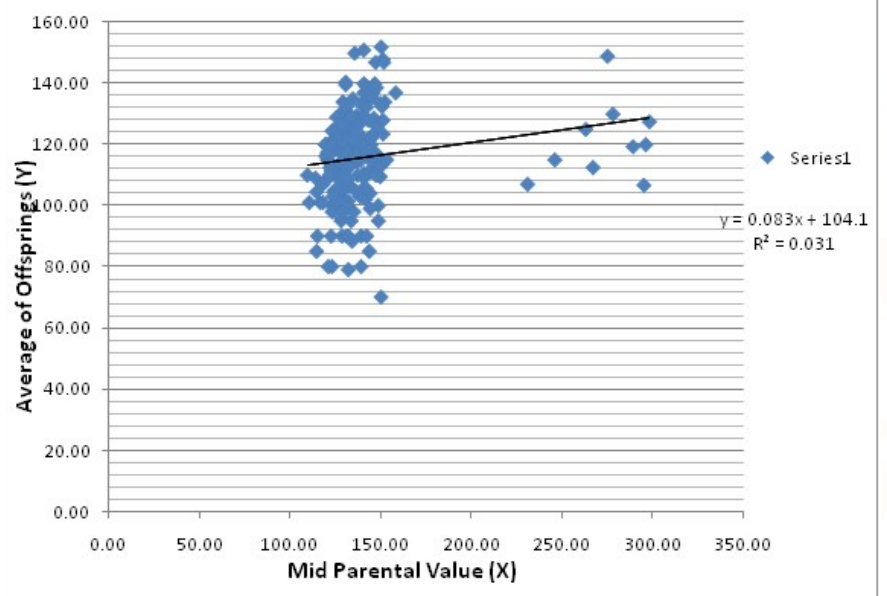

Figure2. Regression analysis for Systolic Blood Pressure 


\section{Conclusion:}

Based on our analysis and comparison of results, it can be concluded that Diastolic blood pressure is more genetically determined than Systolic blood pressure.

\section{Acknowledgments:}

We are thankful to the Principal and Management of the college for financial support and encouragement. We place on record the help given by Ms. Rita Antony, Nurse, College premises, who trained us in operating mercury sphygmomanometer to take precise measurement of Blood Pressure values. We thank all the families who supported us in providing their information.

\section{References:}

1. A Nirmala, Treva Rice, $\mathrm{P}$ Chengal Reddy, $\mathrm{K}$ Sreerama Krishna, P Venkata Ramana and D C Rao (1992). Commingling and Segregation Analysis of Blood Pressure in Consanguineous and Nonconsanguineous Families From Andhra Pradesh, India. American Journal of Human Biology. 4:703-716.

2. G Dayananda and Niranjan Murthy (2009). Blood Pressure Changes in Normotensive Subjects With and Without Family History of Hypertension. Journal of Physiological and Biomedical Sciences. 22:35-37.

3. Heba Alwan, Georg Ehret, Belen Ponte, Menno Pruijm, Daniel Ackermann, Idris Guessous, Jan A Staessen, Kei Asayama, Zoltan Kutalik, Philippe
Vuistiner, Fred Paccaud, Antoinette PechereBertschi, Markus Mohaupt, Bruno Vogt, PierreYves Martin, Michel Burnier and Murielle Bochud. (2015). Heritability of ambulatory and office blood pressure in the Swiss population. Journal of Hypertension. 33:2061-2067.

4. Jerold H Zar (1999). Bio statistical Analysis. $4^{\text {th }}$ Edition.

5. M Singh, A K Singh, S Singh, P Pandey, S Chandra and I S Gambhir (2016). Angiotensinconverting enzyme gene I/D polymorphism increase the susceptibility to hypertension and additive diseases: A study on North Indian patients. Clinical and Experimental Hypertension. 38:3, 305-311 [PubMed].

6. Partha P Majumder, Sujata Nayak, S K Bhattacharya, K K Ghosh, S Pal and B N Mukherjee (1994) An Epidemiological Study of Blood Pressure and Lipid Levels Among Marwaris of Calcutta, India. American Journal of Human Biology. 6:183-194.

7. Partha $\mathrm{P}$ Majumder, S K Bhattacharya, B N Mukherjee and D C Rao (1990). Genetic Epidemiological Study of Blood Pressure in a Sedentary Rural Agricultural Population of West Bengal, India. American Journal of Physical Anthropology. 81:563-572.

8. Taposh Sarkar and Narinder Pal Singh (2015). Epidemiology and Genetics of Hypertension. Journal of The Association of Physicians of India. 63:61-98 [PubMed]. 